\title{
Optimisation of density of infra-red decoy flare pellets by Taguchi method
}

\author{
SUKAMAL ADHIKARY ${ }^{1, *}$, HIMANSHU SEKHAR ${ }^{2}$ and DINESH G THAKUR ${ }^{1}$ \\ ${ }^{1}$ Defence Institute of Advanced Technology, Pune 411025, India \\ ${ }^{2}$ High Energy Materials Research Laboratory, Pune 411021, India \\ e-mail: s_adiks@yahoo.com; himanshudrdo@rediffmail.com; dineshsingh_thakur@yahoo.com
}

MS received 2 October 2018; revised 14 March 2019; accepted 8 April 2019; published online 13 June 2019

\begin{abstract}
Magnesium/Teflon/Viton or MTV pyrotechnic composition has been widely preferred to prepare decoy flares as countermeasures against heat seeking Infra-red (IR) missiles. Though MTV for military applications are available in the global market, the manufacturing process and performance characteristics of these flares have not been explicitly defined. The pellets which are an essential sub-assembly of the flares need to be extensively studied to develop these flares for military applications. The study paper attempts to optimise the density of compacted $50 \mathrm{~mm}$ diameter cylindrical pellets. The pyrotechnic composition is initially subjected to various sensitivity tests namely impact, friction and spark to assess the threshold values of initiation of this composition. Three levels of process parameters for pelleting have been considered and $\mathrm{L}_{27}$ array has been selected to represent the process parameters namely charge mass (A), applied load (B), dwell time (C) and their interactions. The Taguchi robust experiment method arrived at the optimal result as A1B3C3 (100 g of charge mass, 8 tons of applied load and $20 \mathrm{~s}$ of dwell time). Analysis of Variance (ANOVA) highlighted that parameters A and B significantly influenced the density of the pellets. Finally, general regression equation was derived with $\mathrm{R}^{2}$ value of 0.94 .
\end{abstract}

Keywords. Pyrotechnic; MTV; density; Taguchi; ANOVA; regression.

\section{Introduction}

The decoy flares manufactured from pyrotechnic compositions have proven over the years to be the most effective countermeasure against heat seeking missiles. Among the various available pyrotechnic compositions, a composition of magnesium as fuel, polytetrafluoroethylene (PTFE) or Teflon as oxidiser and Viton as binder has become widely acceptable and popular as MTV for decoy flares [1-5]. The maximum IR emission of MTV flares is observed at $1.5-1.3 \mu \mathrm{m}$ with strong selective emission at $4.2-4.6 \mu \mathrm{m}$ due to carbon monoxide and carbon dioxide [2, 3]. The flame temperature attained during combustion of MTV flares is 2000-2200 K [2]. The temperature of hot tail pipe of a jet engine aircraft being of the order of $900-1100 \mathrm{~K}$, an infra-red missile chasing from the rear would lock on to the flare having much higher radiant intensity of the hot tail pipe [3]. Research papers provide information regarding burning characteristics of these flares with variation in chemical constitution and particle size of magnesium as open source literature. However, literature regarding development of flare pellets in different configurations for defence applications, mechanical properties of flares, effect of process parameters on flare performance, optimisation of process

*For correspondence parameters, etc. are somewhat limited probably due to the economic and strategic reasons attributable to the agencies who have developed and marketed these products globally. Although IR intensity, burn time are stated to be performance parameters of IR flares but their dependence on structural integrity of the flare pellets cannot be ruled out. Compacting of MTV powder into pellets and ensuring the compactness of pellets thereby forms an essential activity in the processing of pellets. The controlling parameters for pellets are charge mass, applied load and duration of application. Hence, the present study focuses on understanding the influence of the process parameters to optimize density of standard configuration of $50 \mathrm{~mm}$ cylindrical pellets using Taguchi techniques. Considering the limitations of available literature on this subject, it may be construed that this is possibly the first time Taguchi technique is being implemented to optimize the process parameters of mechanically pressed Infra-red decoy flare pellets.

\section{Design of experiments (DOE) applying Taguchi technique}

In experiments involving various process parameters, one parameter is varied at a time. In 1920s, Fisher has developed the concept of Design of Experiments (DoE) 


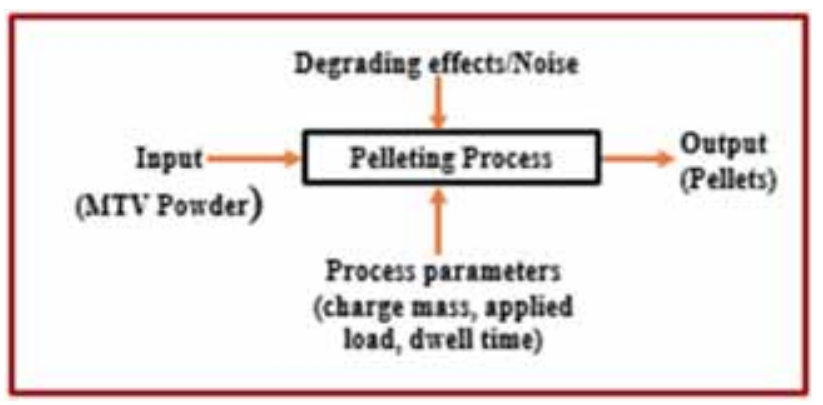

Figure 1. Block diagram pelleting proocess.

and proposed varying of all parameters simultaneously. $\mathrm{He}$ also originated Analysis of Variance (ANOVA), a data analysis technique. To overcome the inherent challenge in DoE of conducting large number of experiments, Orthogonal Array (OA) was propounded in 1940s. In 1950s, Taguchi has amalgamated the benefits of both DoE and OA and evolved the Robust Design Method. The input is the MTV powder and the output are the compacted pellets. The process parameters are charge mass, applied load and the dwell time of the load. During processing, there are noise factors which are uncontrollable like voltage fluctuation, vibration of the compacting plunger, etc. These factors are likely to degrade the quality and consistency in performance of the pellet. Taguchi method maximizes the factor known as $\mathrm{S} / \mathrm{N}$ ratio where $\mathrm{S}$ signifies mean value of the process signal and $\mathrm{N}$ or noise represents the standard deviation. Figure 1 represents block diagram of Taguchi Robust design experiment technique to suit our pelleting process [6].

\section{Details of experiment}

\subsection{Preparation of MTV pyrotechnic composition}

MTV pyrotechnic composition used in this study comprises of magnesium (average particle size 50-75 $\mu \mathrm{m}$ ), Teflon or polytetrafluoroethylene (PTFE) (average particle size $300-500 \mu \mathrm{m})$ and Viton or hexafluoropropene-vinylidenefluoride-copolymer (table 1). The colloidal solution of Viton in acetone is mixed with magnesium powder. The slurry is air dried and Teflon powder is added. The mixture

Table 1. MTV pyrotechnic composition.

\begin{tabular}{lcc}
\hline S1. no. & Chemical & Percentage \\
\hline 01 & Magnesium & $45-50$ \\
02 & PTFE & $45-50$ \\
03 & Viton & $2-8$ \\
\hline
\end{tabular}

is sieved for any sticky mass and allowed to dry overnight to remove any trace of acetone.

\subsection{Qualification testing of pyrotechnic composition}

Pyrotechnic composition needs to be handled with adequate caution since chances of fire/explosion is quite high. Hence, to ascertain the safety limits of the mixture prior to compacting, the impact, friction and spark sensitivity tests are conducted.

3.2a Impact sensitivity evaluation for safe height of impact: The Julius Peters Fall Hammer apparatus is used to determine the impact sensitivity of the powder by Bruceton staircase method. Two kg weight is dropped from varying heights over the sample (figure 2). The height of $50 \%$ of explosion $\left(\mathrm{H}_{50}\right)$ of the sample is obtained from the graph and plotted as height of explosion (y-axis) in $\mathrm{cm}$ vs percentage explosion (x-axis). The value obtained from the graph (y-axis) corresponding to $50 \%$ explosion $\left(\mathrm{H}_{50}\right)$ is considered as the impact sensitivity of the composition.

3.2b Friction sensitivity to sscertain limiting frictional force for handling of mixture: The pyrotechnic composition is subjected to friction sensitivity analysis using a variant of Julius Peters apparatus (figure 3). The test is carried out between $0.5 \mathrm{kgf}$ and $36 \mathrm{kgf}$ dead loads placed at a fixed distance on the loading arm. The test is continued till five successive non-ignitions are obtained at a particular dead load. This dead load is expressed as the friction sensitivity of the sample.

3.2c Spark sensitivity measurement to obviate electro-static initiation: The spark sensitivity measuring equipment is

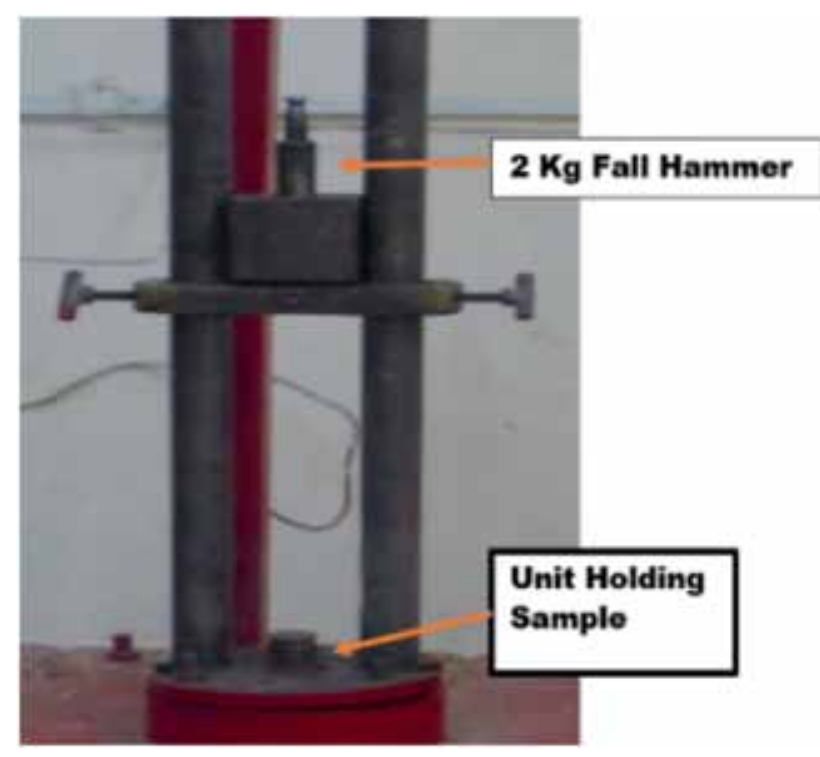

Figure 2. Impact sensitivity tester. 

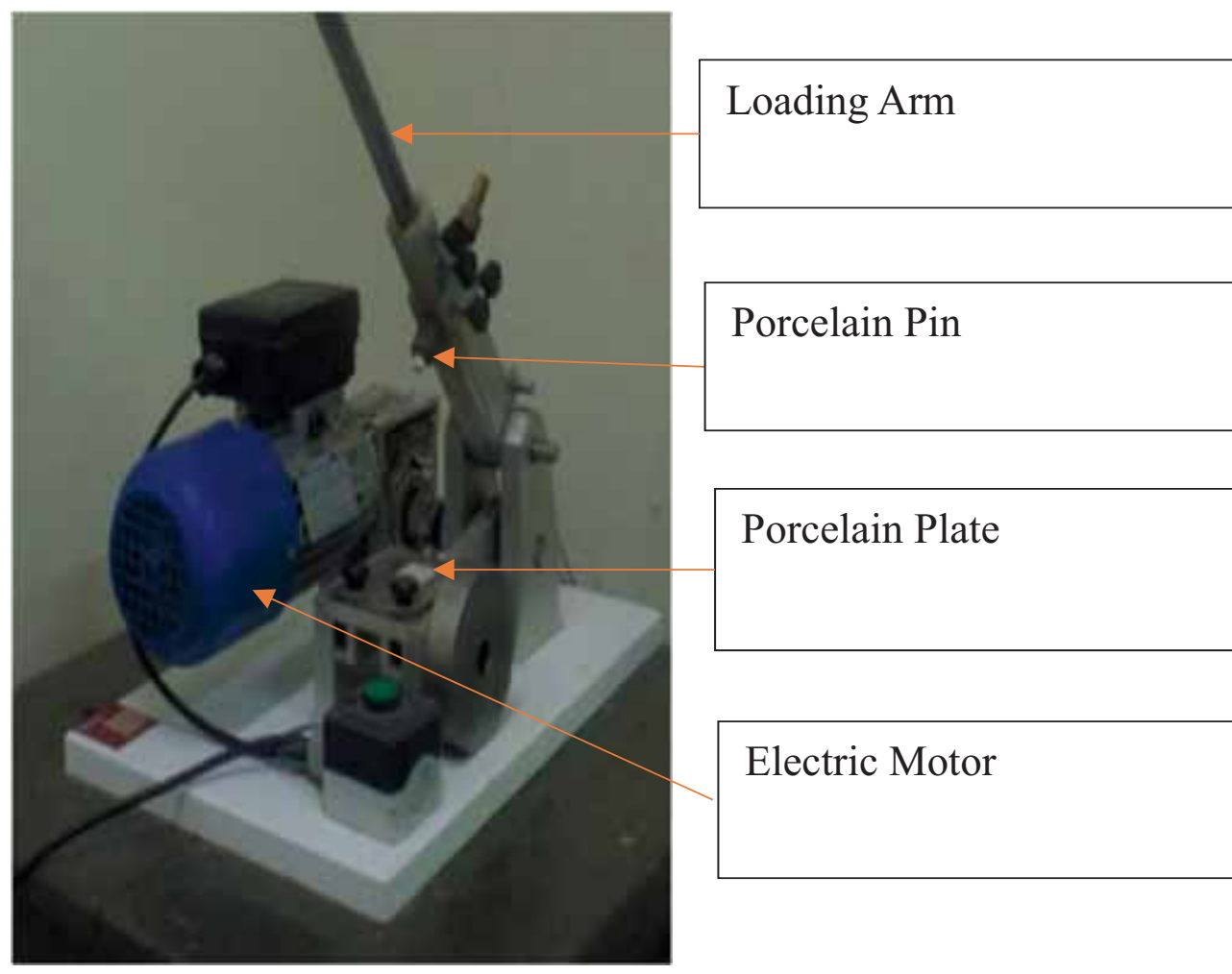

\begin{tabular}{|l|}
\hline Porcelain Pin \\
\hline
\end{tabular}

\section{Porcelain Plate}

Figure 3. Friction sensitivity tester.

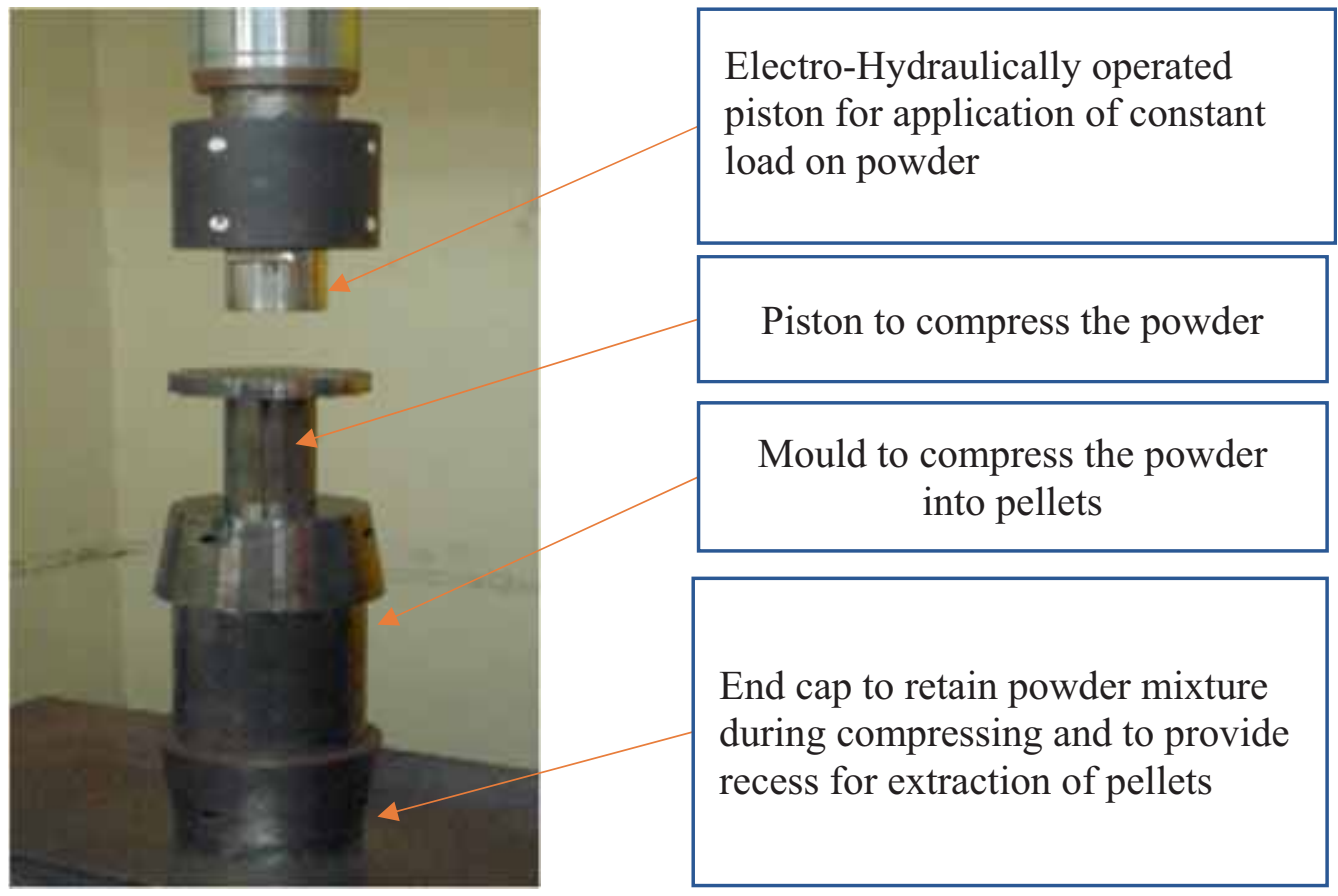

Figure 4. Compacting of powder into pellets.

locally fabricated to measure the threshold energy or the Minimum Ignition Energy (MIE). A spark is generated owing to high voltage difference between cathode and anode resulting in a spark which tends to initiate the explosive composition if the MIE is exceeded. The MIE is denoted as the maximum energy in Joules which would not initiate the composition even after repeated sparks. The MIE is given by: 
Table 2. Design of process parameters and their levels.

\begin{tabular}{lccrrr}
\hline & & & \multicolumn{3}{c}{ Levels } \\
\cline { 3 - 6 } S1. no. & Design factors & Unit & 1 & 2 & 3 \\
\hline 01 & Charge mass (A) & $\mathrm{g}$ & 100 & 120 & 140 \\
02 & Applied load (B) & ton & 6 & 7 & 8 \\
03 & Dwell time (C) & $\mathrm{s}$ & 10 & 15 & 20 \\
\hline
\end{tabular}

Table 3. Evaluation of degree of freedom (DoF).

\begin{tabular}{lcc}
\hline S1. No. & Factor and interactions & Degree of freedom (DoF) \\
\hline 01 & Charge mass (A) & $(3$ levels- 1$)=2$ \\
02 & Applied load (B) & $(3$ levels- 1$)=2$ \\
03 & Dwell time (C) & $(3$ levels- 1$)=2$ \\
04 & Interaction I (A*B) & $2 * 2=4$ \\
05 & Interaction II (B*C) & $2 * 2=4$ \\
06 & Interaction III (A*C) & $2 * 2=4$ \\
& Total & 18 \\
\hline
\end{tabular}

$$
\mathrm{MIE}=0.5 * \mathrm{C} * \mathrm{~V}^{2}
$$

Where, MIE is given in millivolts, $\mathrm{C}$ is the capacitance in micro-farads and $\mathrm{V}$ is the applied voltage in kilo volts.

\subsection{Preparation of pellets}

After ascertaining the sensitivity values of the composition, the powder is compacted by mechanical pressing (figure 4). A locally fabricated hardened steel mould of $50 \mathrm{~mm}$ diameter is used to prepare cylindrical pellets by varying three process parameters namely charge mass, applied load for compacting and duration of application of load. The cross-sectional area of the pellets is maintained constant. The influence of the three factors on density were studied earlier by performing preliminary experimental investigations with charge mass varying from 40 to $160 \mathrm{~g}$, applied load varying from 1 to 9 tons and dwell time varying from 5 to $20 \mathrm{~s}$. Encouraging results for density were obtained with charge mass varying between 100 and $140 \mathrm{~g}$, applied load between 6 and 8 tons and dwell time between 10 and $20 \mathrm{~s}$. Accordingly, three levels of each of the process parameters

Table 4. $\mathrm{L}_{27}\left(3^{13}\right)$ Orthogonal array representing the design factors and the assigned interactions.

\begin{tabular}{|c|c|c|c|c|c|c|c|c|c|c|c|c|c|}
\hline \multirow[b]{2}{*}{ Expt. no. } & \multicolumn{13}{|c|}{ Columns } \\
\hline & $\begin{array}{c}1 \\
(\mathrm{~A})\end{array}$ & $\begin{array}{c}2 \\
(\mathrm{~B})\end{array}$ & $\begin{array}{c}3 \\
(\mathrm{AXB})\end{array}$ & $\begin{array}{c}4 \\
(\mathrm{AXB})\end{array}$ & $\begin{array}{c}5 \\
(\mathrm{C})\end{array}$ & $\begin{array}{c}6 \\
(\mathrm{AXC})\end{array}$ & $\begin{array}{c}7 \\
(\mathrm{AXC})\end{array}$ & $\begin{array}{c}8 \\
(\mathrm{BXC})\end{array}$ & $\begin{array}{l}9 \\
-\end{array}$ & $\begin{array}{l}10 \\
-\end{array}$ & $\begin{array}{c}11 \\
(\mathrm{BXC})\end{array}$ & $\begin{array}{l}12 \\
-\end{array}$ & $\begin{array}{l}13 \\
-\end{array}$ \\
\hline 1 & 1 & 1 & 1 & 1 & 1 & 1 & 1 & 1 & 1 & 1 & 1 & 1 & 1 \\
\hline 2 & 1 & 1 & 1 & 1 & 2 & 2 & 2 & 2 & 2 & 2 & 2 & 2 & 2 \\
\hline 3 & 1 & 1 & 1 & 1 & 3 & 3 & 3 & 3 & 3 & 3 & 3 & 3 & 3 \\
\hline 4 & 1 & 2 & 2 & 2 & 1 & 1 & 1 & 2 & 2 & 2 & 3 & 3 & 3 \\
\hline 5 & 1 & 2 & 2 & 2 & 2 & 2 & 2 & 3 & 3 & 3 & 1 & 1 & 1 \\
\hline 6 & 1 & 2 & 2 & 2 & 3 & 3 & 3 & 1 & 1 & 1 & 2 & 2 & 2 \\
\hline 7 & 1 & 3 & 3 & 3 & 1 & 1 & 1 & 3 & 3 & 3 & 2 & 2 & 2 \\
\hline 8 & 1 & 3 & 3 & 3 & 2 & 2 & 2 & 1 & 1 & 1 & 3 & 3 & 3 \\
\hline 9 & 1 & 3 & 3 & 3 & 3 & 3 & 3 & 2 & 2 & 2 & 1 & 1 & 1 \\
\hline 10 & 2 & 1 & 2 & 3 & 1 & 2 & 3 & 1 & 2 & 3 & 1 & 2 & 3 \\
\hline 11 & 2 & 1 & 2 & 3 & 2 & 3 & 1 & 2 & 3 & 1 & 2 & 3 & 1 \\
\hline 12 & 2 & 1 & 2 & 3 & 3 & 1 & 2 & 3 & 1 & 2 & 3 & 1 & 2 \\
\hline 13 & 2 & 2 & 3 & 1 & 1 & 2 & 3 & 2 & 3 & 1 & 3 & 1 & 2 \\
\hline 14 & 2 & 2 & 3 & 1 & 2 & 3 & 1 & 3 & 1 & 2 & 1 & 2 & 3 \\
\hline 15 & 2 & 2 & 3 & 1 & 3 & 1 & 2 & 1 & 2 & 3 & 2 & 3 & 1 \\
\hline 16 & 2 & 3 & 1 & 2 & 1 & 2 & 3 & 3 & 1 & 2 & 2 & 3 & 1 \\
\hline 17 & 2 & 3 & 1 & 2 & 2 & 3 & 1 & 1 & 2 & 3 & 3 & 1 & 2 \\
\hline 18 & 2 & 3 & 1 & 2 & 3 & 1 & 2 & 2 & 3 & 1 & 1 & 2 & 3 \\
\hline 19 & 3 & 1 & 3 & 2 & 1 & 3 & 2 & 1 & 3 & 2 & 1 & 3 & 2 \\
\hline 20 & 3 & 1 & 3 & 2 & 2 & 1 & 3 & 2 & 1 & 3 & 2 & 1 & 3 \\
\hline 21 & 3 & 1 & 3 & 2 & 3 & 2 & 1 & 3 & 2 & 1 & 3 & 2 & 1 \\
\hline 22 & 3 & 2 & 1 & 3 & 1 & 3 & 2 & 2 & 1 & 3 & 3 & 2 & 1 \\
\hline 23 & 3 & 2 & 1 & 3 & 2 & 1 & 3 & 3 & 2 & 1 & 1 & 3 & 2 \\
\hline 24 & 3 & 2 & 1 & 3 & 3 & 2 & 1 & 1 & 3 & 2 & 2 & 1 & 3 \\
\hline 25 & 3 & 3 & 2 & 1 & 1 & 3 & 2 & 3 & 2 & 1 & 2 & 1 & 3 \\
\hline 26 & 3 & 3 & 2 & 1 & 2 & 1 & 3 & 1 & 3 & 2 & 3 & 2 & 1 \\
\hline 27 & 3 & 3 & 2 & 1 & 3 & 2 & 1 & 2 & 1 & 3 & 1 & 3 & 2 \\
\hline
\end{tabular}


Table 5. Sensitivity test results.

\begin{tabular}{lcc}
\hline Sl. no. & Sensitivity test & Values obtained \\
\hline 01 & Impact sensitivity & $\mathrm{H}_{50}=37.5 \mathrm{~cm}$ \\
02 & Friction sensitivity & Insensitive up to $36 \mathrm{kgf}$ \\
03 & Spark sensitivity & No ignition up to $500 \mathrm{~mJ}$ \\
\hline
\end{tabular}

namely charge mass (A), applied load (B) and dwell time (C) are considered to optimise their influence on density as shown in table 2 .

\section{Design of process parameters}

\subsection{Selection of orthogonal array (OA)}

The guiding factor for choosing OA is that the total number of experimental trials should be more than the combined degree of freedom (DoF) of the individual factors and their interactions. The DoF is one less than the level of the factor. The DoF is as shown in table 3. Therefore, the number of experiments necessary to arrive at consensus result should be more than twenty. This confirms that OA $\mathrm{L}_{27}$ would be appropriate for the present experiment. The matrix of $\mathrm{L}_{27} \mathrm{OA}$ along with the positioning of the factors and their interactions is reflected in table $4[6,7]$.

\subsection{Measurement of density of pellets}

The pellets formed have constant cross-sectional area but the length of the pellets varied with the process parameters. Since magnesium present in the pyrotechnic composition reacts violently with water, the conventional measurement of density applying Archimedes principle could not be adopted. The density is calculated by dividing the charge mass of each pellet by volume of the pellet. Three samples are taken per experiment and five readings taken per sample. The average of these fifteen readings are recorded as the mean length of each pellet and multiplied with the constant cross-sectional area to obtain volume of pellet.

\section{Experimental results and discussion}

\subsection{Sensitivity test results}

The sensitivity test results obtained are provided in table 5 .

\subsection{S/N ratio analysis}

Taguchi method restricts the variance of the output to a minimum by controlling interference of uncontrollable factors (noise). Since density in our study is to be
Table 6. Experimental results and $\mathrm{S} / \mathrm{N}$ ratio.

\begin{tabular}{lcc}
\hline Experiment No. & Density $(\mathrm{g} / \mathrm{cc})$ & $\mathrm{S} / \mathrm{N}$ ratio $(\mathrm{dB})$ \\
\hline 1 & 1.569 & 3.91246 \\
2 & 1.579 & 3.97864 \\
3 & 1.590 & 4.14730 \\
4 & 1.603 & 4.17420 \\
5 & 1.620 & 4.28097 \\
6 & 1.636 & 4.32332 \\
7 & 1.649 & 4.38121 \\
8 & 1.663 & 4.41784 \\
9 & 1.680 & 4.52168 \\
10 & 1.575 & 3.94561 \\
11 & 1.587 & 3.97864 \\
12 & 1.607 & 4.02794 \\
13 & 1.616 & 4.12032 \\
14 & 1.630 & 4.19030 \\
15 & 1.645 & 4.29158 \\
16 & 1.661 & 4.40739 \\
17 & 1.676 & 4.48548 \\
18 & 1.688 & 4.54745 \\
19 & 1.557 & 3.84577 \\
20 & 1.565 & 3.89029 \\
21 & 1.574 & 3.94009 \\
22 & 1.590 & 4.02794 \\
23 & 1.603 & 4.09867 \\
24 & 1.609 & 4.13112 \\
25 & 1.610 & 4.13652 \\
26 & 1.621 & 4.19566 \\
27 & 1.630 & 4.24375 \\
\hline & & \\
\hline
\end{tabular}

Table 7. Response table of mean $\mathrm{S} / \mathrm{N}$ ratio.

\begin{tabular}{lccc}
\hline Level & Charge mass (A) & Applied load (B) & Dwell time (C) \\
\hline 1 & 4.238 & 3.963 & 4.106 \\
2 & 4.222 & 4.182 & 4.168 \\
3 & 4.057 & 4.371 & 4.242 \\
Rank & 2 & 1 & 3 \\
Delta & 0.181 & 0.408 & 0.136 \\
\hline
\end{tabular}

The total mean $\mathrm{S} / \mathrm{N}$ ratio of the highest rank design parameter is $4.172 \mathrm{~dB}$.

maximised, $\mathrm{S} / \mathrm{N}$ ratio needs to be calculated using LB (Larger the Better) criterion represented as [6]:

$$
\mathrm{S} / \mathrm{N}=-10 \log _{10}\left\{1 / \mathrm{n} *\left(\Sigma 1 / \mathrm{y}^{2}\right)\right\}
$$

The density values obtained through experiments vis a vis the $\mathrm{S} / \mathrm{N}$ ratios are given in table 6 . Mean $\mathrm{S} / \mathrm{N}$ ratio for each level of the factors A, B and C is tabulated in table 7 . The delta value represents the difference between the largest and least value of each column. The higher this value, more predominant would be the influence of this factor on the performance. From table 7 it is evident that applied load (B) has the greatest influence on the density of the pellets. The main effects of the parameters are plotted in figure 5 . Figure 5(a) indicates that $100 \mathrm{~g}$ of charge mass (A1) is most 


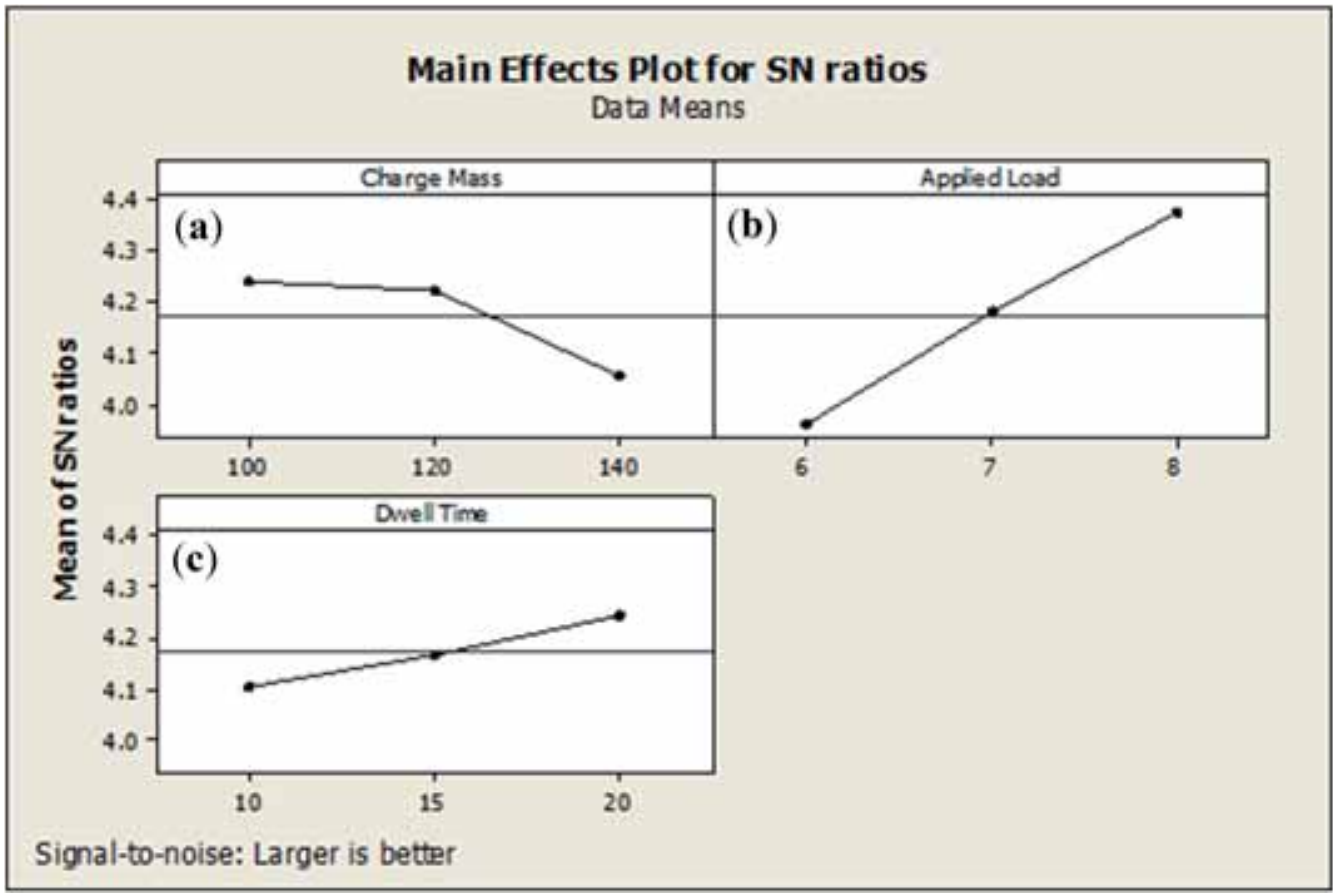

Figure 5. Main effect plot for $\mathrm{S} / \mathrm{N}$ ratio.

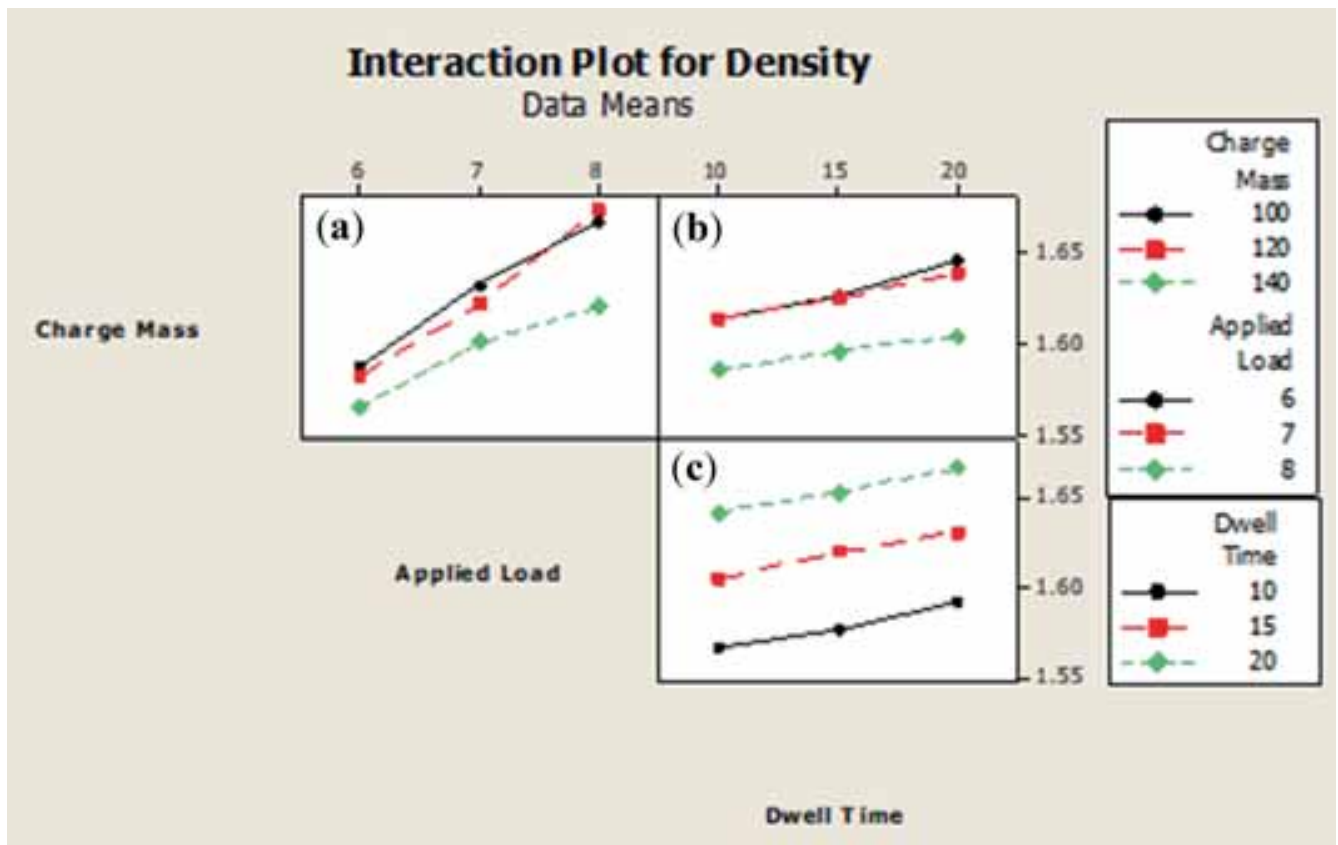

Figure 6. Interaction effects plot for mean density.

preferred for minimizing noise factor applying Larger the Better criterion. Applying the same logic, figures 5(b) and 5 (c) conform that 8 tons of applied load (B3) and $20 \mathrm{~s}$ of dwell time (C3), respectively would achieve optimum result condition. Thus, we could confirm that $\mathrm{A} 1 \mathrm{~B} 3 \mathrm{C} 3$ would be the most preferred combination of process parameters to produce the optimized density of pellets under the existing conditions. 
Table 8. Results of analysis of variance (ANOVA).

\begin{tabular}{lccccc}
\hline Source of variation & Degrees of freedom & Sum of squares & Mean square & F & $\%$ Contribution \\
\hline Charge mass (A) & 2 & 0.0063102 & 0.0031551 & $113.24^{\mathrm{a}}$ & 17.04 \\
Applied load (B) & 2 & 0.0260247 & 0.0130123 & $467.04^{\mathrm{a}}$ & 70.30 \\
Dwell time (C) & 2 & 0.0028940 & 0.0014470 & $51.94^{\mathrm{a}}$ & 7.82 \\
A*B & 4 & 0.0013578 & 0.0003394 & $12.18^{\mathrm{a}}$ & 3.67 \\
B*C & 4 & 0.0000387 & 0.0000097 & 0.35 & 0.11 \\
A*C & 4 & 0.0001698 & 0.0000424 & 0.46 \\
Error & 8 & 0.0002229 & 0.0000279 & & 0.6 \\
Total & 26 & 0.0370180 & & & \\
\hline
\end{tabular}

${ }^{\mathrm{a}}$ Significant parameters, interactions.

Significant parameters $\mathrm{F}_{0.01,2,8}=99.4, \mathrm{~F}_{0.05,2,8}=19.4, \mathrm{~F}_{0.05,4,8}=6.04$ [8].

Table 9. Results of confirmation test.

\begin{tabular}{|c|c|c|c|}
\hline \multirow[b]{2}{*}{ Level } & \multirow{2}{*}{$\begin{array}{l}\text { Initial parameter } \\
\text { combination } \\
\text { A2B } 2 \mathrm{C} 2\end{array}$} & \multicolumn{2}{|c|}{$\begin{array}{c}\text { Optimal parameter } \\
\text { combination }\end{array}$} \\
\hline & & $\begin{array}{l}\text { Prediction } \\
\text { A2B3C3 }\end{array}$ & $\begin{array}{c}\text { Experimentation } \\
\text { A2B } 3 \mathrm{C} 3\end{array}$ \\
\hline $\begin{array}{l}\text { Density } \\
\qquad(\mathrm{g} / \mathrm{cc})\end{array}$ & 1.63 & 1.6794 & 1.688 \\
\hline $\begin{array}{l}\text { S/N ratio } \\
(\mathrm{dB})\end{array}$ & 4.19030 & 4.50601 & 4.54745 \\
\hline
\end{tabular}

Improvement of $\mathrm{S} / \mathrm{N}$ ratio is $0.357 \mathrm{~dB}$.

The interaction between three process parameters have been represented considering two variables at a time in figure 6 . The most conspicuous interactions will have the plots intersecting each other. Figure 6(a) depicting the interaction between the charge mass and applied load is the most prominent as the upper two curves intersect each other. This is more of a qualitative assessment than a quantitative one. Figure 6(b) representing the interaction between charge mass and dwell time bears some significance in terms of interaction of these two process parameters while figure $6(\mathrm{c})$ representing the interaction between applied load and dwell time is the least significant as all three plots are clearly separated from each other. Thus, the plots between the three combinations of the process parameters reveal that the interaction of charge mass and applied load has the highest influence in the process followed by interaction between charge mass and dwell time. The interaction between applied load and dwell time is nearly insignificant as also could be confirmed from ANOVA table 8.

\subsection{Analysis of variance (ANOVA)}

The ANOVA table is represented in table 8. The F-value and $\%$ Contribution illustrates the significance of each factor/interaction. The F-values are compared with the
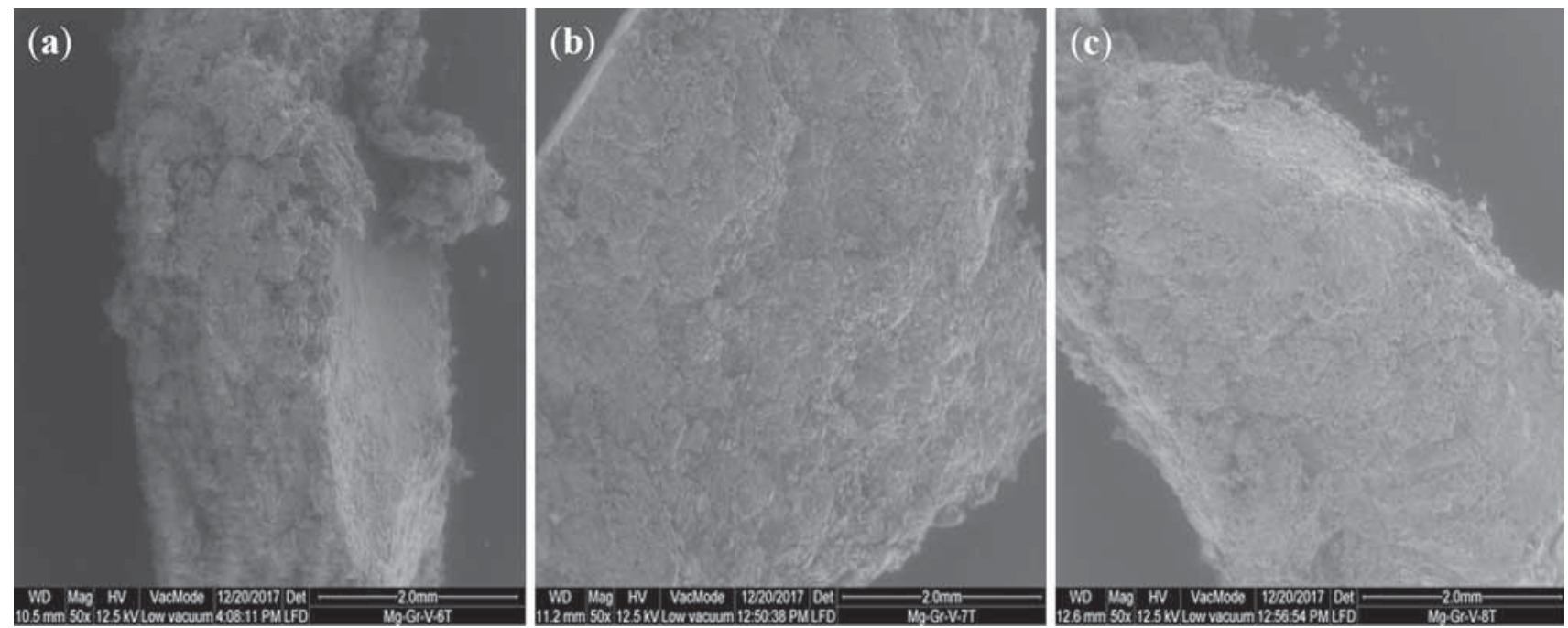

Figure 7. SEM images of pellets at $50 \times$ magnification. (a) 6 tons, (b) 7 tons and (c) 8 tons of loads. 

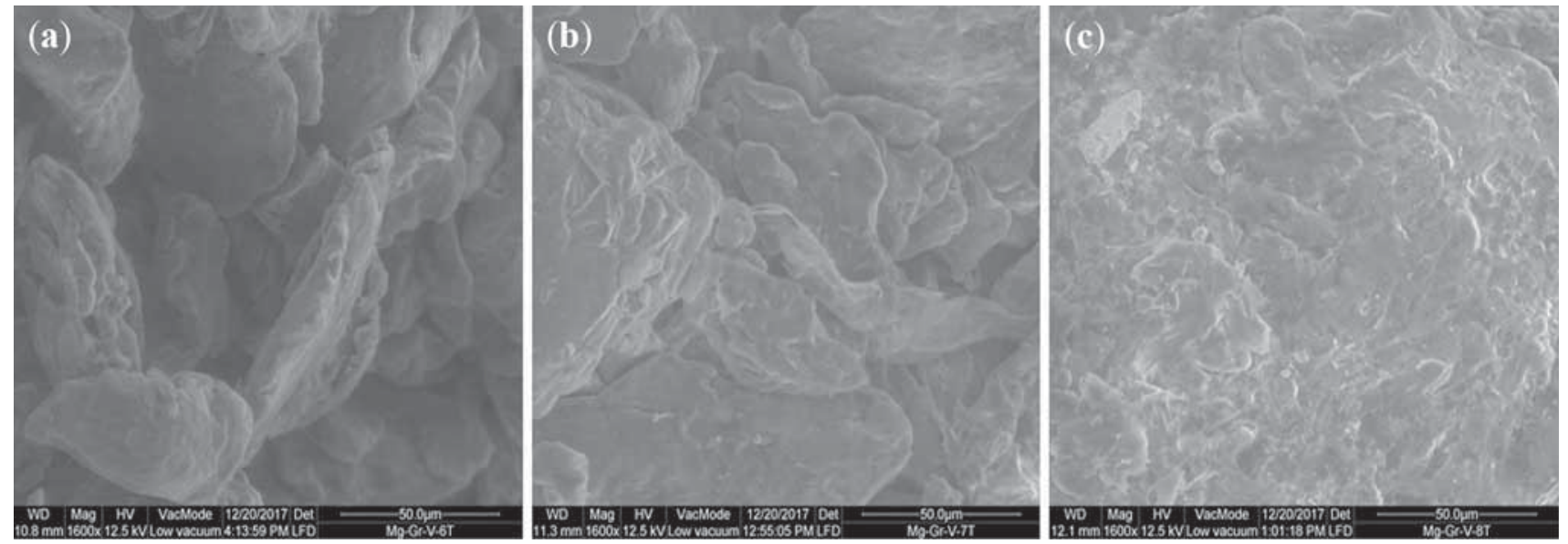

Figure 8. SEM images of pellets at 1600× magnification. (a) 6 tons, (b) 7 tons and (c) 8 tons of loads.

standard F-values tabulated for various confidence levels. In table 8 , parameters $\mathrm{B}$ and $\mathrm{A}$ are most significant at confidence level of $99 \%$, followed by parameter $\mathrm{C}$, at confidence level of $95 \%$. Also, $\mathrm{A} * \mathrm{~B}$ interaction is observed to have predominant effect on density at confidence level of $95 \%$.

\subsection{Confirmation test}

The confirmation test (table 9) is to validate that the optimum condition as suggested by Taguchi technique actually provided improvement in density of pellets. The density of pellets obtained during 27 experiments varied from 1.557 $\mathrm{g} / \mathrm{cc}$ to $1.688 \mathrm{~g} / \mathrm{cc}$ which resulted in $8.4 \%$ variation in density. The optimal condition A1B3C3 was achieved by Taguchi method at $\mathrm{S} / \mathrm{N}$ ratio of 4.52168 against an initial parameter combination of $\mathrm{A} 2 \mathrm{~B} 2 \mathrm{C} 2$ value of 4.19030 . The density value increased from $1.63 \mathrm{~g} / \mathrm{cc}$ to $1.68 \mathrm{~g} / \mathrm{cc}$. Though the enhancement in value from the initial parameter combination $\mathrm{A} 2 \mathrm{~B} 2 \mathrm{C} 2$ is a mere $3.1 \%$ but it needs to be appreciated that the optimum condition has resulted in approx. $38.17 \%$ enhancement of density as explained below:

$$
\begin{aligned}
\text { Enhancement in density }= & (1.68-1.63) \\
& * 100 /(1.688-1.557) \\
= & 38.17 \%
\end{aligned}
$$

Thus, optimal result was achieved as A1B3C 3 by Taguchi method under the prevailing conditions.

The study of variation of three process parameters and their interactive influence on density of pellets has been the objective of this study. It is observed that the optimised density of pellets is attained in case of A1B3C 3 combination. This implies that $100 \mathrm{~g}$ of charge mass needs to be compacted at 8 tons load for $20 \mathrm{~s}$. The parameter having maximum influence during pelleting is the applied load. The increase in applied load is expected to enhance the compacting due to reduction of voids or inter-particle distance. This happens due to deformation and brittle fracture of particles which occupy the voids. However, with reduction in voids, the surface area of contact between particles increases which resists further deformation/fracture of the particles.

In case of variation of charge mass, it is natural that the load needs to be transmitted across the layers for effective compacting. With increase in charge mass beyond $100 \mathrm{~g}$, the lower layers are not sufficiently compacted.

The influence of dwell time is somewhat insignificant compared to the other two factors as is evident from the interactive plot (figure 6(c)) and ANOVA table (table 8).

It may be understood that under the prevailing experimental conditions and with the results obtained, Taguchi method has predicted the optimum conditions of density with variation of process parameters. This result may vary with change in configuration of the pellets.

\subsection{General regression analysis}

The final step of this study is obtaining a general regression equation utilising Minitab software. The Regression Equation derived is as follows:

$$
\begin{aligned}
\text { Density }= & 1.089+0.00187 * \mathrm{M}+0.0755 * \mathrm{~L}+0.0067 \\
& * \mathrm{~T}-0.00031 \mathrm{M} * \mathrm{~L}-3.5 \mathrm{e}-005 \mathrm{M} * \mathrm{~T}
\end{aligned}
$$

where density is in $\mathrm{g} / \mathrm{cc}$, charge mass (M) is in $\mathrm{g}$, applied load (L) is in tons and dwell time (T) is in s.

The $\mathrm{R}^{2}$ value obtained is 0.94 . In Regression analysis, the regression co-efficient is denoted by the factor $\mathrm{R}^{2}$ and its standardized value is considered as $\mathbf{0 . 9}$. In the present case, the value is 0.94 which is higher thereby confirming that the fit of the experimental data is satisfactory.

The inter-particle distance is reduced with higher applied loads as evident in SEM images in figure 7 and the structure becomes more homogenous. Higher magnification in 
figure 8 reveals that the particle size reduces with higher loads due to deformation/fracture of particles. The surface contact area between particles increases which resists further deformation/fracture of particles.

\section{Conclusion}

The highlights of the results are as follows:

- Three process parameters namely charge mass (A), applied load (B) and dwell time (C) are varied in three levels each to obtain optimum conditions for density of pellets.

- Applied load has maximum influence on density followed by charge mass. Dwell time has relatively insignificant influence on density. This has also been validated by ANOVA analysis.

- Optimum condition obtained is A1B3C3 which resulted in approximately 38\% increase in density.

- It is expected that for this configuration of pellet, with further increase of charge mass, the applied load would not be effectively transmitted to the lower layers of the powders and compacting would not be proper which would affect the structural integrity of the pellets.

- The applied load of 8 tons is also expected to optimize density of pellets by maximum deformation/fracture of the particles which would minimize the inter-particle voids. This load is likely to vary with change in configuration of the pellets.

- General regression equation was derived with a $\mathrm{R}^{2}$ value of 0.94 .

\section{References}

[1] Kubota N and Serizawa C 1987 Combustion process of Mg/ TF pyrotechnics. Propellants Explos. Pyrotech. 12: 145-148

[2] Koch E C and Dochnahl Axel 2000 IR emission behaviour of magnesium/teflon/viton (MTV) Compositions. Propellants Explos. Pyrotech. 25: 37-40

[3] Koch E C 2001 Review on pyrotechnic aerial infrared decoys. Propellants Explos. Pyrotech. 26: 3-11

[4] Koch E C 2002 Metal-fluorocarbon-pyrolants: III: development and application of magnesium/teflon/viton (MTV). Propellants Explos. Pyrotech. 27: 262-266

[5] Koch E C 2002 Metal-Fluorocarbon-Pyrolants: IV: Thermochemical and Combustion Behaviour of magnesium/Teflon/ Viton (MTV). Propellants Explos. Pyrotech. 27: 340-351

[6] Phadke Madhav S 1989 Quality Engineering Using Robust Design, New Jersey: Prentice-Hall

[7] Ross P J 1996 Taguchi Techniques for Quality Engineering, 2nd Ed, New York: McGraw-Hill

[8] Montgomery D C 2001 Design and Analysis of Experiments. New York: Wiley 